\title{
Ang-(1-7) protects skeletal muscle function in aged mice
}

\author{
Ying Li ${ }^{1}$, Jiao Song ${ }^{1}$, Yangyang Jiang ${ }^{1}$, Xue Yang ${ }^{1}$, Li Cao ${ }^{1}$, Chun Xiao ${ }^{1}$, Suli Li ${ }^{2}$, Birong Dong ${ }^{1}$ and Xiaoli Huang ${ }^{1,3^{*}}$
}

\begin{abstract}
Background: The angiotensin-converting enzyme 2 (ACE2)/angiotensin 1-7 (Ang-(1-7)) axis has been shown to protect against the age-associated decline in skeletal muscle function. Here, we investigated the protective effects of ACE2 in mitigating the age-associated decline of skeletal muscle function and to identify the potential underlying molecular mechanisms.

Methods: We measured the expression levels of Ang-(1-7) in C57BL/6J mice of different ages and correlated these levels with measures of skeletal muscle function. We also investigated the expression of myocyte enhancer factor $2 \mathrm{~A}(\mathrm{MEF} 2 \mathrm{~A})$ in ACE2 knockout (ACE2KO) mice and its relationship with muscle function. We then treated aged ACE2KO mice for four weeks with Ang-(1-7) and characterized the levels of MEF2A and skeletal muscle function before and after treatment. We assessed the impact of Ang-(1-7) on the growth and differentiation of C2C12 cells in vitro and assessed changes in expression of the glucose transporter type 4 (Glut4).
\end{abstract}

Results: Aged mice showed reduced skeletal muscle function and levels of Ang-(1-7) expression in comparison to young and middle-aged mice. In ACE2KO mice, skeletal muscle function and MEF2A protein expression were significantly lower than in age-matched wild-type (WT) mice. After one month of Ang-(1-7) treatment, skeletal muscle function in the aged ACE2KO mice improved, while MEF2A protein expression was similar to that in the untreated group. In C2C12 cells, Ang-(1-7) was shown to promote along with the upregulated expression of Glut4.

Conclusions: The ACE2/ Ang-(1-7) axis has a protective function in skeletal muscle and administration of exogenous Ang-(1-7) can delay the age-related decline in the function of skeletal muscle.

Keywords: angiotensin-converting enzyme 2, skeletal muscle, angiotensin 1-7, aging

\section{Introduction}

The process of aging is correlated with pronounced decreases in skeletal muscle mass, reduced muscular function and a general decline in physical fitness. In the clinic, these manifestations are commonly associated with sarcopenia and frailty [1]. Selective androgen agonists can be prescribed to partially increase muscle mass; however,

\footnotetext{
* Correspondence: huangxiaoli@scu.edu.cn

${ }^{1}$ The Center of Gerontology and Geriatrics, National Clinical Research Center for Geriatrics, West China Hospital, Sichuan University, Sichuan, China

${ }^{3}$ The Center of Gerontology and Geriatrics, National Clinical Research Center for Geriatrics,West China Hospital, Sichuan University, 37 Guoxuexiang, Sichuan providence 610041 Chengdu, P.R. China

Full list of author information is available at the end of the article
}

these agents fail to improve muscle function. Although myostatin-neutralizing antibody and activin IIB receptor blockers can significantly increase muscle mass and partially improve muscle function, their clinical benefits are unclear $[2,3]$. The identification of safe and clinically effective drugs capable of managing the age-related loss of muscle function and mass represents a significant challenge with a high potential for clinical impact.

The Renin-angiotensin system (RAS), a peptidergic signaling pathway, is widely expressed in the cardiovascular system, kidneys, and lungs. The association between RAS and the angiotensin-converting enzyme (ACE)-angiotensin II (Ang II) axis is well documented. However, the angiotensin-converting enzyme 2 (ACE2) -

(c) The Author(s). 2021 Open Access This article is licensed under a Creative Commons Attribution 4.0 International License, which permits use, sharing, adaptation, distribution and reproduction in any medium or format, as long as you give appropriate credit to the original author(s) and the source, provide a link to the Creative Commons licence, and indicate if changes were made. The images or other third party material in this article are included in the article's Creative Commons licence, unless indicated otherwise in a credit line to the material. If material is not included in the article's Creative Commons licence and your intended use is not permitted by statutory regulation or exceeds the permitted use, you will need to obtain permission directly from the copyright holder. To view a copy of this licence, visit http://creativecommons.org/licenses/by/4.0/. The Creative Commons Public Domain Dedication waiver (http://creativecommons.org/publicdomain/zero/1.0/) applies to the data made available in this article, unless otherwise stated in a credit line to the data. 
angiotensin 1-7 (Ang-(1-7)) pathway has been reported to compete with ACE/Ang II pathway [4].

The main pathological features of sarcopenia are directly related to the age-related decline in the mass and structure of skeletal muscles and the ACE/Ang II pathway has been found to be closely associated with skeletal muscle loss [5]. Ang II, through binding to the angiotensin II type 1 receptor (AT1R), reduces microvascular perfusion, glucose uptake, and insulin sensitivity in mouse muscle fibers $[6,7]$. Attempts have been made to improve skeletal muscle function and delay age-related muscle atrophy by pharmacological antagonism of the ACE-Ang II-AT1R pathways using AT1R antagonists or ACE inhibitors (ACEIs). However, randomized controlled clinical trials have so far demonstrated unsatisfactory results. Shrikrishna and colleagues showed that ACEI did not significantly improve lower extremity skeletal muscle function in elderly patients with severe obstructive pulmonary illness [8]. Similarly, the TRAIN trial demonstrated that ACEI had no significant effects on the activity capacity of elderly patients [9].

The ACE2 - Ang-(1-7) pathway is the protective arm of RAS. Several studies have reported that Ang-(1-7) attenuates muscle dysfunction in animal models. Acuña et al. [10] found that Ang-(1-7) decreased fibrosis and improved muscle function in Duchenne muscular dystrophy mice. In chronic liver disease mice, Ang-(1-7) prevented declining muscle strength and function, reducing fatigue [11]. Thus, activation of the ACE2 - Ang(1-7) pathway might contribute to the improvement of muscle decline in age-associated muscular disorders. The main aim of the current research was to investigate the role of the ACE2/Ang-(1-7) pathway on age-related skeletal function decline. Additionally, we attempted to clarify the possible underlying molecular mechanisms of this protective action.

\section{Methods}

\section{Experimental design}

C57BL/6J mice of different ages were used for the in vivo experiments. An ACE2-KO mouse model (C57BL/6J background) was also used for functional studies. All mice were bought from the Laboratory Animal Research Institute of the Chinese Academy of Medical Sciences. In vitro assays were performed using the C2C12 mouse myoblast cell line. Experiments were performed to determine skeletal muscle function and the expression of Ang (1-7) and Ang II in old (20 months), middle-aged (12 months), and young (3 months) C57BL/6J mice. Further, the skeletal muscle function and the expression of myocyte enhancer factor $2 \mathrm{~A}$ (MEF2A) were determined in young (4 months) and old (16 months) ACE2-KO mice and their wild-type agematched controls.
Old (16 months) ACE2-KO mice received Ang-(1-7) (APEXBio, Houston, TX, USA, product No. A1041) administered through osmotic minipumps (Alzet-Durect, Cupertino, CA, USA) with $400 \mathrm{ng} / \mathrm{kg} / \mathrm{min}$ of for four weeks. Skeletal muscle function and the expression of MEF2A were compared before and after treatment. In the control group, the ACE2-KO mice were received $0.9 \%$ normal saline. Each group had five mice. $\mathrm{C} 2 \mathrm{C} 12$ cells (from the cell bank of the Chinese Academy of Sciences) were cultured in Dulbecco's Modified Eagle Medium (DMEM) supplemented with $10 \%$ fetal bovine serum (Gibco, Grand Island, NY, USA). To induce cell differentiation, cells were cultured for $48 \mathrm{~h}$ in DMEM containing $2 \%$ horse serum (Gibco, Grand Island, NY, USA), supplemented with $10^{-8} \mathrm{~mol} / \mathrm{L}$ of Ang-(1-7) or the same volume of PBS. After incubation, the cellular differentiation levels and the expression of glucose transporter type 4 (Glut4), MEF2A, myosin heavy chain $(\mathrm{MHC})$, and creatine kinase, muscle (CKM) proteins were evaluated. All in vivo protocols were approved by the Animal Committee of West China Hospital, Sichuan University.

\section{Testing of skeletal muscle function}

Skeletal muscle function was evaluated by measuring the grip forelimb strength and the number of falls in a treadmill test. The grip strength of the mouse forelimb was measured using a tester of grip strength (YLS-13 A, Jinan Yiyan Technology Development Co., Ltd, Jinan, China.). For each mouse, five measurements were performed at 5 -seconds intervals and the average value was recorded. The treadmill test used an experimental animal treadmill (ZH-PT, Shanghai Kehuai Instrument Co., Ltd, Shanghai, China., Shanghai, China) with the track speed set at $9 \mathrm{~m} / \mathrm{min}$. The number of falls from the track within 5 min was recorded. For each mouse, measurements were recorded in triplicate and performed at 5 -minute intervals. The average number of falls was recorded.

\section{Preparation of mouse skeletal muscle}

Mice were anesthetized by using pentobarbital $(45 \mathrm{mg} /$ $\mathrm{kg}$ ) and the gastrocnemius and soleus muscles were removed and frozen in liquid nitrogen for subsequent analyses.

\section{Determination of the levels of Ang-(1-7) and Ang II in mouse skeletal muscles}

Frozen skeletal muscle samples $(30 \mathrm{mg})$ were thawed and homogenized in a cold mixture of methanol $(500 \mu \mathrm{l})$ and phosphate buffer $(500 \mu \mathrm{l}, \mathrm{pH} 7.4,50 \mathrm{mM})$, and then incubated at $4{ }^{\circ} \mathrm{C}$ for $1 \mathrm{~h}$ and centrifuged at 100,000 g for $20 \mathrm{~min}$. The concentrations of Ang II and Ang-(1-7) were measured in the supernatants using ELISA kits 
(Cloud-Clone Corp., Houston, TX, USA) Cat. No. CEA005Mu (Ang II) and CES085Mi (Ang-(1-7)) according to the manufacturers' instructions. The levels of Ang II and Ang-(1-7) were measured in muscle samples obtained from five mice in each experimental group.

\section{Determination of MEF2A protein levels in mouse skeletal muscle}

The expression of MEF2A was determined by Western blotting. The absorbance of each protein band was determined using Image-Pro Plus 6.0 software.

\section{C2C12 cell culture and differentiation}

C2C12 cells were cultured in DMEM containing $2 \%$ horse serum. To analyze cell differentiation, Ang-(1-7) was added and the cells were incubated at $37^{\circ} \mathrm{C}$ for an additional 48 h. PBS was added to the control cultures. The fusion index was calculated as the ratio of the number of nuclei in myocytes with two or more nuclei versus the total number of nuclei.

\section{Protein expression in differentiating $\mathrm{C} 2 \mathrm{C} 12$ cells}

The expression of MHC, creatine kinase, muscle CKM, Glut4, and MEF2A proteins was determined by Western blotting in $\mathrm{C} 2 \mathrm{C} 12$ cells using three independent experiments. Following the evaluation of differentiation, the cells were collected, rinsed with PBS, incubated on ice in RIPA lysis buffer, and centrifuged at 100,000 $\mathrm{g}$ for $20 \mathrm{~min}$ at $4{ }^{\circ} \mathrm{C}$. The total protein concentration in the supernatants was quantified by the BCA method. Proteins $(20 \mu \mathrm{g} / \mathrm{lane})$ were separated on SDS-PAGE, transferred to nitrocellulose membranes, and blocked as described above. Primary antibodies against MHC (Proteintech, Rosemont, IL, USA, Cat. No. 10799-1-AP), CKM (Proteintech, Cat. No. 18712-1-AP), Glut4 (Proteintech, Rosemont, IL, USA, Cat. No. 21048-1-AP), and MEF2A (Proteintech, Rosemont, IL, USA, Cat. No. 12382-1-AP) were incubated overnight at $4{ }^{\circ} \mathrm{C}$. The blots were then probed with secondary antibodies and visualized using a chemiluminescence detection kit. Protein expression was normalized to that of GAPDH (AC036; ABclonal). The absorbance of each protein band was determined using the Image-Pro Plus 6.0 software.

\section{Statistical methods}

Data were expressed as means \pm SD (five animals per group, three independent experiments) and analyzed utilizing the SPSS 20.0 computer program package. A ttest was utilized for comparison between two groups. One-way ANOVA or the Kruskal-Wallis test were used for comparison between several groups. A $P$-value threshold of 0.05 was considered statistically significant.

\section{Results}

The grip strength of old mice was observed to be decreased compared to young and middle-aged mice (young: $1.93 \pm 0.14 \mathrm{~g} / \mathrm{g}$, middle-aged: $2.34 \pm 0.29 \mathrm{~g} / \mathrm{g}$, old: $1.58 \pm 0.06 \mathrm{~g} / \mathrm{g}$, all $P<0.05$ ) (Fig. $1 \mathrm{~A}$ ). In the treadmill test, the number of falls in old mice $(17.86 \pm 3.85)$ was higher than in the young $(13.14 \pm 2.60)$ and middle-aged $(12.71 \pm 2.29)$ mice $(P<0.05)$ (Fig. 1 B). The levels of Ang-(1-7) in the skeletal muscles of old mice were found to be lower compared to the young and middleaged mice. The levels of Ang II were greater than in young and middle-aged mice compared to old mice $(P<$ 0.05 in all cases) (Fig. $1 \mathrm{C}$ ). These data indicated that the function of mouse skeletal muscle and the expression of Ang-(1-7) were both reduced with aging. In contrast, the expression of Ang II increased with aging in mice.

We compared the motor abilities of ACE2-KO and wild-type (WT) mice at various ages and found that the grip strength of ACE2-KO mice was considerably lower than age-matched WT animals $(P<0.05)$. Moreover, the grip strength of young ACE2-KO mice was similar to that of old WT mice $(2.80 \pm 0.34 \mathrm{~g} / \mathrm{g}$ vs. $2.63 \pm 0.13 \mathrm{~g} / \mathrm{g}$, $P>0.05$ ) (Fig. 2 A).

In the treadmill experiments, the number of falls was significantly higher in the ACE2-KO mice in comparison to the age-matched WT animals $(P<0.05)$. The number of treadmill falls in young ACE2-KO was comparable to that in old WT mice $(15.33 \pm 2.16$ vs. $14.00 \pm 1.41, P>$ 0.05) (Fig. 2 B).

The changes in the levels of MEF2A protein expression in the mouse skeletal muscles at different ages indicated that the level of MEF2A in both WT and ACE2$\mathrm{KO}$ mice decreased with age (both $\mathrm{P}<0.05$ ). However, the expression of MEF2A was lower in ACE2-KO than in WT mice $(P<0.05)$ (Fig. $2 \mathrm{C}$ ).

After four weeks of Ang-(1-7) injections, the grip strength of aged ACE2-KO increased $(P<0.05)$ (Fig. $3 \mathrm{~A}$ ), and the number of falls in the treadmill test decreased $(P<0.05)$ (Fig. $3 \mathrm{~B})$. However, the expression of MEF2A protein in skeletal muscle remained similar to that in the normal saline group $(P>0.05)$ (Fig. $3 C$ ). Both skeletal muscle function and MEF2A protein expression decreased in aged ACE2-KO mice. The administration of Ang-(1-7) in ACE2-KO mice increased their motor ability without producing a significant change in the MEF2A protein level.

The influences of Ang-(1-7) on the differentiation of $\mathrm{C} 2 \mathrm{C} 12$ cells in vitro were evaluated. After the exposure to Ang-(1-7) for $48 \mathrm{~h}, \mathrm{C} 2 \mathrm{C} 12$ cells formed tentacle-like extensions that had fibroblast-like morphologies. Importantly, tubular connections between cells were formed (Fig. 4 A). The fusion index of the Ang-(1-7) intervention group was higher than that of the control group. Western blotting showed that Ang-(1-7) 


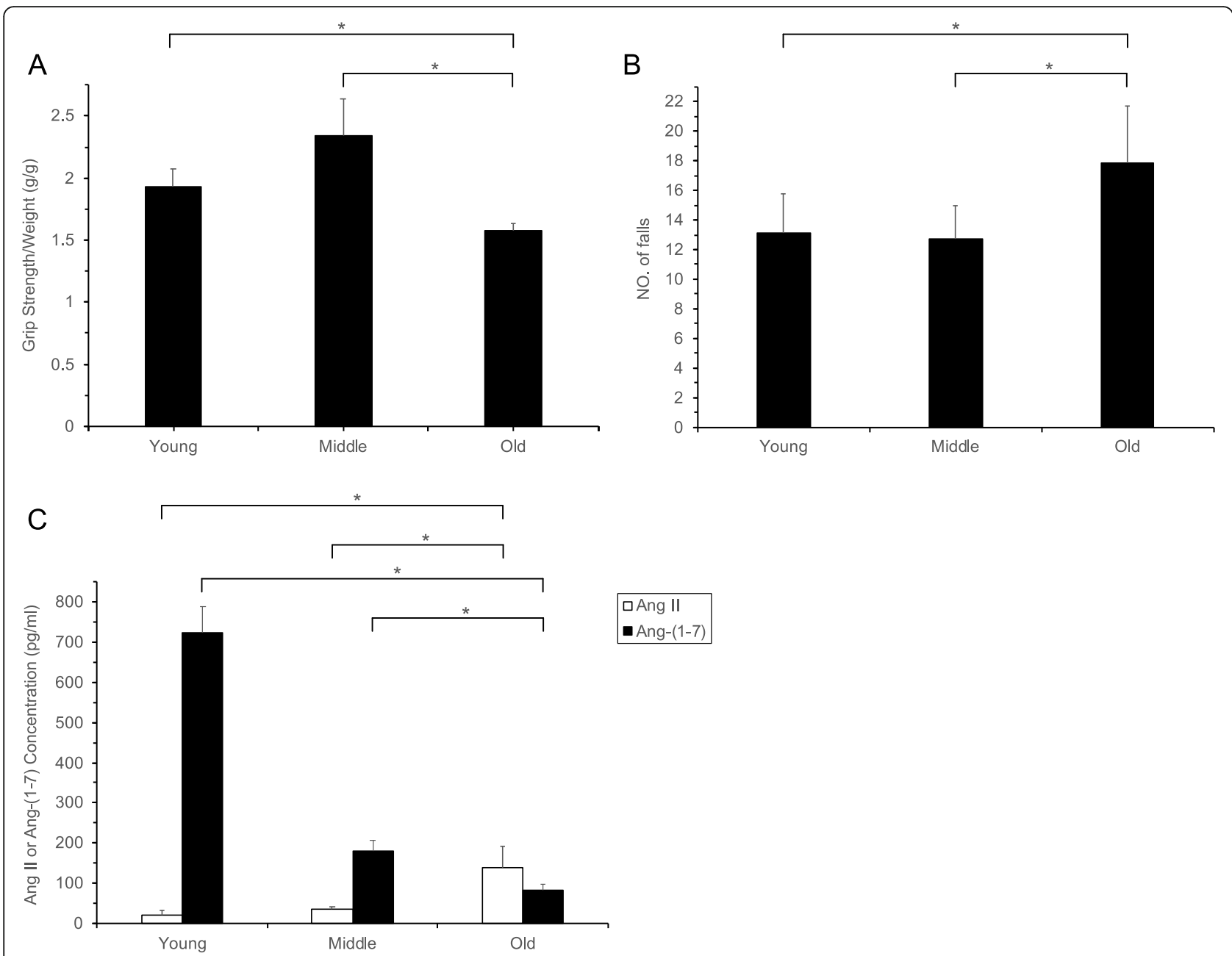

Fig. 1 (A) grip strength, (B) numbers of falls, and (C) Ang-(1-7) and Ang II expression in the treadmill test in mice of different ages. ${ }^{*} P<0.05$, determined by the ANOVA with Least Significance Difference test or Kruskal-Wallis one way ANOVA test ( $n=5$ mice per group).

treatment upregulated the expression of Glut4 protein but down-regulated the levels of MEF2A, MHC, and CKM (Fig. 4 B). Treatment with Ang-(1-7) promoted the differentiation and growth of $\mathrm{C} 2 \mathrm{C} 12$ cells and enhanced the expression of Glut4.

\section{Discussion}

In this study, it was found that with increasing age, both the skeletal muscle function and the tissue levels of Ang-(1-7) decreased in mice. The skeletal muscle function in old ACE2-KO mice was reduced and the motor ability of young ACE2-KO mice was equivalent to that of old wild-type mice. However, the motor function of aged ACE2-KO mice increased after Ang-(1-7) treatment. We investigated the possible underlying mechanisms of these effects and found that Ang-(1-7) treatment resulted in the upregulated expression of Glut4 while not affecting the expression of MEF2A.
These results indicate that Ang-(1-7) enhances skeletal muscle motor function in aging mice by promoting cellular glucose metabolism.

Our experiments demonstrated that the older mice had reduced grip strength and experienced a higher number of falls compared to young mice in the treadmill test. The skeletal muscles of aged animals showed decreased levels of Ang-(1-7) and higher levels of Ang II compared to young mice. Previous findings have shown that the ACE/Ang II axis is correlated with skeletal muscle insulin resistance, atrophy and fibrosis and antagonizes the ACE2/Ang-(1-7) axis [12, 13]. The ACE/ Ang II axis reduces microvascular perfusion, glucose uptake, and the insulin sensitivity of insulin during skeletal muscle atrophy $[6,7]$.

In contrast, ACE2/Ang-(1-7) axis is beneficial to skeletal muscles as it acts to improve insulin resistance and prevent fibrosis $[14,15]$. The current study showed that the decline in skeletal muscle function in aged mice was 


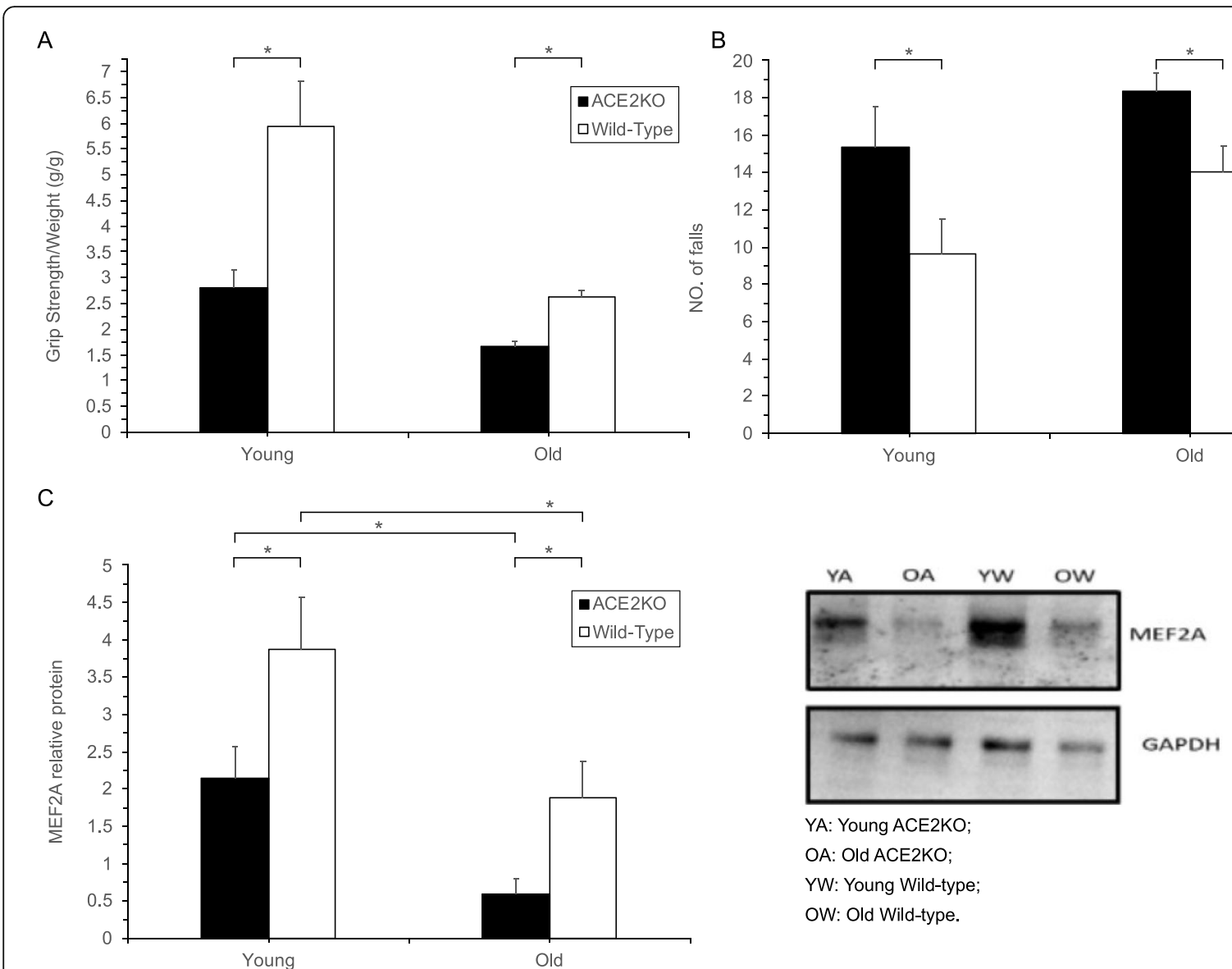

Fig. 2 (A) grip strength, (B) numbers of falls, and (C) MEF2A expression in ACE2-KO and WT mice. ${ }^{*} P<0.05$, determined by t-test $(n=5$ mice per group).

accompanied by a decrease in the tissue concentration of Ang-(1-7) and an enhancement in the concentration of Ang II. These findings suggest that as mice age, an imbalance in the RAS system may develop in skeletal muscles. These changes cause decreased performance of the protective ACE2/Ang-(1-7) axis and an increase in the deleterious activity of the ACE/Ang II pathway.

Further analysis showed that at any age, the skeletal muscle performance in ACE2-KO mice was worse than in WT animals, and the muscle performance in young ACE2-KO mice was similar to that in aged WT mice. Continuous injection of Ang-(1-7) in old ACE2-KO mice increased motor capacity which was consistent with the findings of Takeshita and Hikari $[16,17]$. The deletion of the $A C E 2$ gene accelerated the age-associated damage to skeletal muscle function in mice whilst the administration of Ang-(1-7) alleviated this type of damage.

In animal models of heart failure, ACE2 improves cardiac function and ventricular remodeling by the production of Ang-(1-7) resulting in improved survival [18]. In another study, the treatment of ACE2-KO mice by exogenous Ang-(1-7) reduced cardiac lipid toxicity and atherosclerosis caused by a high-fat diet and prevented the development of heart failure [19]. Similarly, in skeletal muscle, Ang-(1-7) has been demonstrated to enhance microvascular perfusion and glucose uptake and to improve insulin resistance $[14,20]$.

In a mouse model of Duchenne muscular dystrophy, the upregulation of ACE2 expression or the administration of Ang-(1-7) were observed to reduce the skeletal muscle fibrosis and to ameliorate skeletal muscle structure and function $[10,21,22]$. Our data are also supported by the work from the Yamamoto laboratory that showed that ACE2 deficiency accelerated the age-related loss of skeletal muscle mass and functional decline. However, the Yamamoto group found that the protective effect of ACE2 on skeletal muscles may be achieved through the non-Ang-(1-7)-MAS pathway [17, 23]. Furthermore, apart from the ACE2/Ang-(1-7) pathway, ACE2 is also involved in other biological pathways including the ACE2/Apelin pathway that acts to reverse sarcopenia and age-related muscle loss and functional decline [24]. Further in vivo studies are required to 


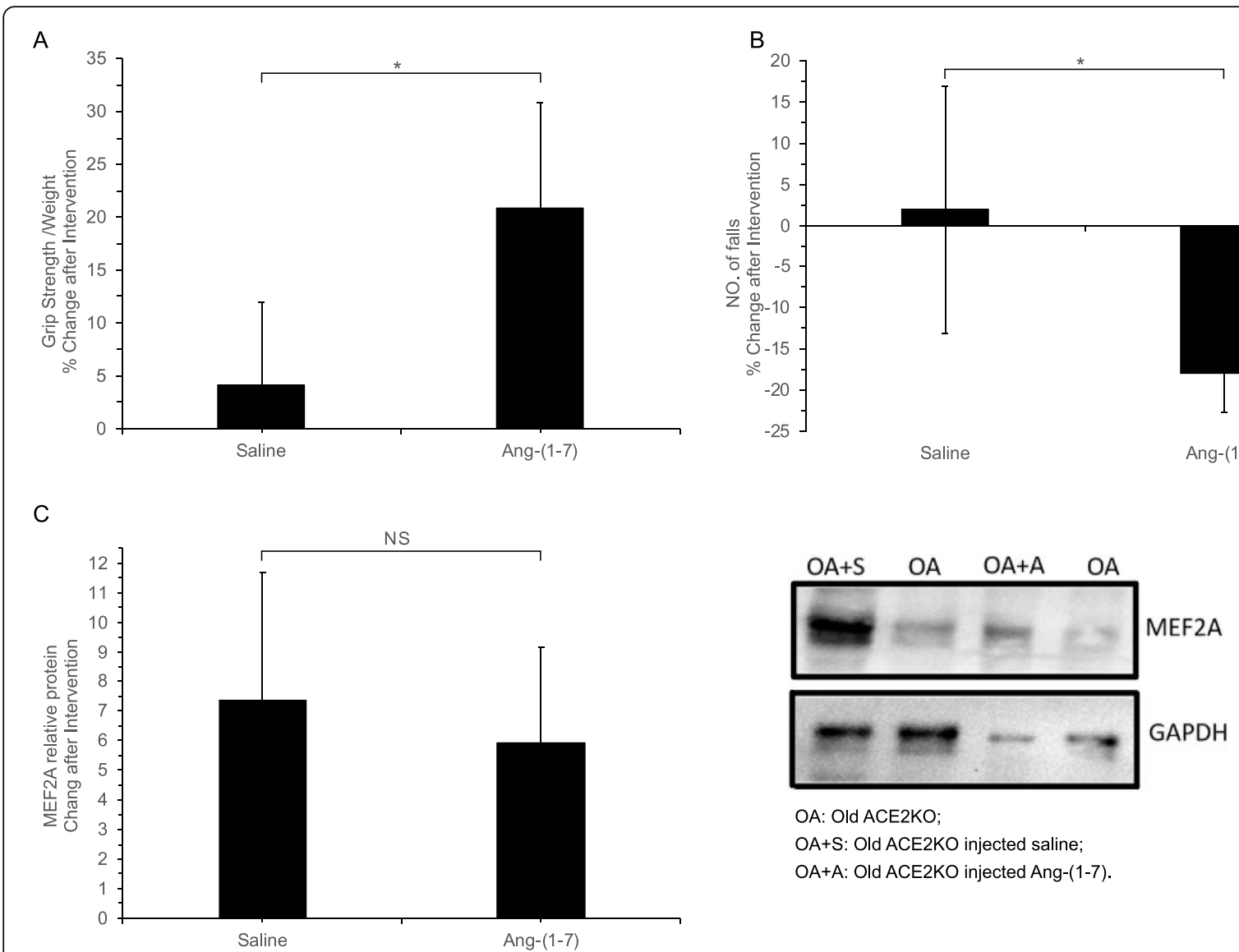

Fig. 3 (A) Changes in grip strength, (B) numbers of falls, and (C) MEF2A expression after Ang-(1-7) intervention in older ACE2-KO mice. * $P<0.05$, determined by t-test ( $n=5$ mice per group).

identify the pathways through which ACE2 achieves its protective effect on skeletal muscle during aging.

Although ACE2 may exert its biological effects in ACE2-KO mice through a variety of pathways, the delivery of exogenous Ang-(1-7) was shown to slow the process of age-associated skeletal muscle decline resulting in increased muscle function. We then explored the specific mechanism underlying the impact of exogenous Ang-(1-7) in vitro. After the exposure of $\mathrm{C} 2 \mathrm{C} 12$ cells to Ang-(1-7), the expression of Glut4 increased and the expression of MEF2A decreased. Takeda and coworkers [25] reported that the expression of Glut4 protein was reduced in the skeletal muscle of ACE2-KO mice. After treatment with Ang-(1-7), the expression of Glut4 increased in ACE2-KO mice. In addition, they found that Ang-(1-7) increased insulin-stimulated glucose uptake both in vivo and in vitro. Glut4 is responsible for glucose transport in skeletal muscle cells and regulates glucose homeostasis to reduce insulin resistance [26, 27]. Regular exercise can improve the expression of Glut4 in the muscles thereby increasing glucose uptake capacity and improving muscle function [26]. The results presented in the current study also suggested that Ang-(1-7) might promote glucose metabolism in muscle cells.

There are some limitations in the current study. We did not measure the Glut4 levels in skeletal muscle of ACE2-KO mice. We also did not perform a glucose tolerance test in mice or measure glucose uptake in the $\mathrm{C} 2 \mathrm{C} 12$ cells. Previous studies found that Ang-(1-7) enhanced the glucose tolerance and improved insulin resistance in rodents $[25,28,29]$. In vitro, Ang-(1-7) treatment enhanced insulin mediated glucose uptake [25]. These studies focused on the relationship between Ang-(1-7) and metabolic regulation, but did not investigated skeletal muscle aging. Thus, further research will be required to investigate the precise involvement of glucose metabolism in the Ang-(1-7)-induced protective mechanism in skeletal muscle aging.

\section{Conclusions}

An imbalance of the RAS system may be responsible for the age-associated decline in skeletal muscle function. The ACE2/Ang-(1-7) axis has a protective role in skeletal muscles and the administration of exogenous Ang- 


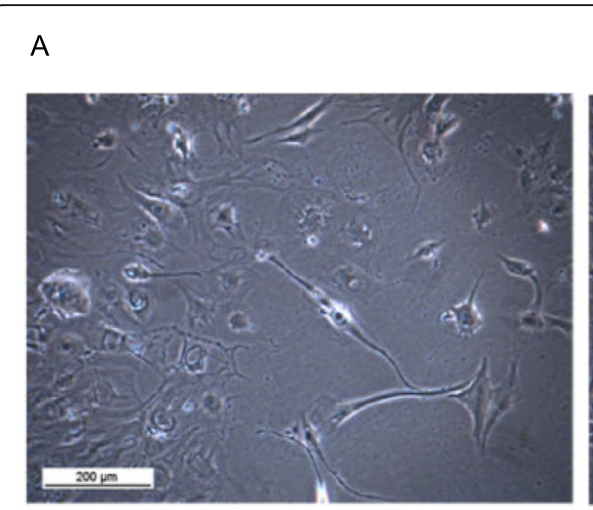

PBS

B

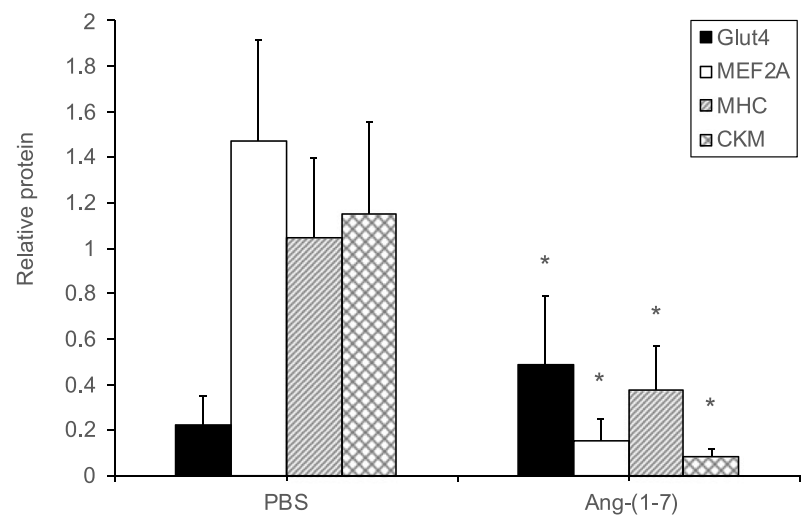

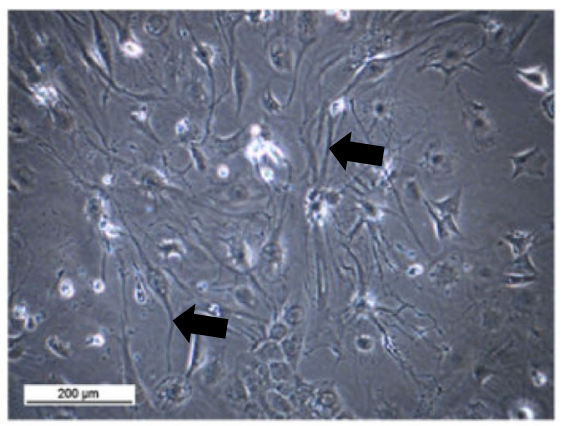

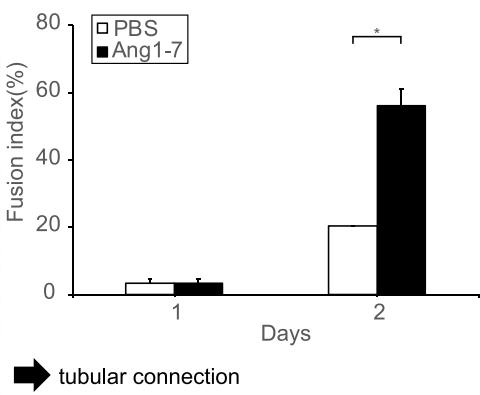

Ang-(1-7)
Fig. 4 (A) Differentiation and (B) Glut4, MEF2A, MHC, and CKM expression of C2C12 cells after Ang-(1-7) intervention. ${ }^{*} P<0.05$, determined by ttest between intervention and control groups ( $n=3$ independent experiments per group).
12

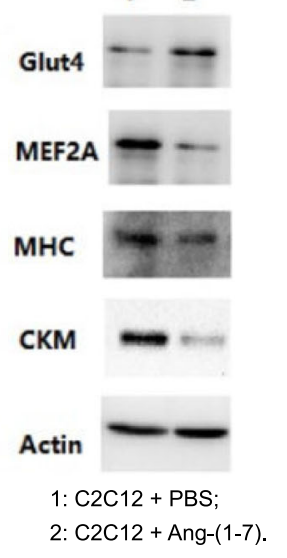

(1-7) can prevent the deterioration in skeletal muscle function. The possible mechanism is that Ang-(1-7) improves the glucose metabolism in muscle cells. This study provides new perspectives for the treatment of age-related sarcopenia with Ang-(1-7).

\section{Abbreviations}

ACE: angiotensin-converting enzyme; Ang: angiotensin; MEF2A: myocyte enhancer factor 2 A; ACE2KO: ACE2knockout; Glut4: glucose transporter type 4; RAS: Renin-angiotensin system; ACEl: Angiotensin converting enzyme inhibitor; MHC: myosin heavy chain; CKM: creatine kinase muscle

\section{Acknowledgements}

Not applicable.

\section{Authors' contributions}

$X L H, Y L$ and BRD led the development of the study concept. $Y L, X L H, J S, Y Y J$, $X Y$ and $L C$ drafted the manuscript. YL, CX, and SLL performed the experiments. The author(s) read and approved the final manuscript.

\section{Statement}

We confirmed that all methods were performed in accordance with the relevant regulations of the Animal Committee of the West China Hospital, Sichuan University ( reference number : 2,019,277 A ), and the study was carried out in compliance with the ARRIVE guideline.

\section{Funding}

This study was partly supported by the National Natural Science Foundation of China (81501197), Sichuan Province Science and Technology Support Program (2019YFG0194, 2020YFG0086), National Clinical Research Center for Geriatrics, West China Hospital, Sichuan University (Z20191010)。

\section{Availability of data and materials}

The datasets used and/or analyzed during the current study are available from the corresponding author on reasonable request.

\section{Declarations}

\section{Ethics approval and consent to participate}

The in vivo protocols were approved by the Animal Committee of the West China Hospital, Sichuan University.

\section{Consent for publication}

Not applicable.

\section{Competing interests}

The authors declare that they have no competing interests.

\section{Author details}

${ }^{1}$ The Center of Gerontology and Geriatrics, National Clinical Research Center for Geriatrics, West China Hospital, Sichuan University, Sichuan, China. ${ }^{2}$ Chengdu Koamy Biotechnology Co, Ltd, Chengdu, Sichuan, China. ${ }^{3}$ The Center of Gerontology and Geriatrics, National Clinical Research Center for Geriatrics,West China Hospital, Sichuan University, 37 Guoxuexiang, Sichuan providence 610041 Chengdu, P.R. China. 
Received: 3 March 2021 Accepted: 6 September 2021

Published online: 21 September 2021

\section{References}

1. Morley JE: Frailty and sarcopenia in elderly. Wien Klin Wochenschr 2016, 128(Suppl 7):439-445.

2. Chen LK, Woo J, Assantachai P, Auyeung TW, Chou MY, lijima K, Jang HC, Kang L, Kim M, Kim S et al: Asian Working Group for Sarcopenia: 2019 Consensus Update on Sarcopenia Diagnosis and Treatment. J Am Med Dir Assoc 2020, 21(3):300-307 e302.

3. Cruz-Jentoft AJ, Sayer AA: Sarcopenia. The Lancet 2019, 393(10191):2636-2646.

4. Iwai M, Horiuchi M: Devil and angel in the renin-angiotensin system: ACEangiotensin I-AT1 receptor axis vs. ACE2-angiotensin-(1-7)-Mas receptor axis. Hypertens Res 2009, 32(7):533-536.

5. Yoshida T, Tabony AM, Galvez S, Mitch WE, Higashi Y, Sukhanov S, Delafontaine P: Molecular mechanisms and signaling pathways of angiotensin I-induced muscle wasting: potential therapeutic targets for cardiac cachexia. Int J Biochem Cell Biol 2013, 45(10):2322-2332.

6. Chai W, Wang W, Dong Z, Cao W, Liu Z: Angiotensin II Receptors Modulate Muscle Microvascular and Metabolic Responses to Insulin In Vivo. Diabetes 2011, 60(11):2939-2946.

7. Chai W, Wang W, Liu J, Barrett EJ, Carey RM, Cao W, Liu Z: Angiotensin II type 1 and type 2 receptors regulate basal skeletal muscle microvascular volume and glucose use. Hypertension 2010, 55(2):523-530.

8. Shrikrishna D, Tanner RJ, Lee JY, Natanek A, Lewis A, Murphy PB, Hart N, Moxham J, Montgomery HE, Kemp PR et al: A randomized controlled trial of angiotensin-converting enzyme inhibition for skeletal muscle dysfunction in COPD. Chest 2014, 146(4):932-940.

9. Cesari M, Pedone C, Incalzi RA, Pahor M: ACE-inhibition and physical function: results from the Trial of Angiotensin-Converting Enzyme Inhibition and Novel Cardiovascular Risk Factors (TRAIN) study. J Am Med Dir Assoc 2010, 11(1):26-32.

10. Acuna MJ, Pessina P, Olguin H, Cabrera D, Vio CP, Bader M, Munoz-Canoves $P$, Santos RA, Cabello-Verrugio C, Brandan E: Restoration of muscle strength in dystrophic muscle by angiotensin-1-7 through inhibition of TGF-beta signalling. Hum Mol Genet 2014, 23(5):1237-1249.

11. Aguirre F, Abrigo J, Gonzalez F, Gonzalez A, Simon F, Cabello-Verrugio C: Protective Effect of Angiotensin 1-7 on Sarcopenia Induced by Chronic Liver Disease in Mice. Int J Mol Sci 2020, 21(11).

12. Cabello-Verrugio C, Morales MG, Rivera JC, Cabrera D, Simon F: Reninangiotensin system: an old player with novel functions in skeletal muscle. Med Res Rev 2015, 35(3):437-463.

13. Frantz EDC, Prodel E, Braz ID, Giori IG, Bargut TCL, Magliano DC, Nobrega ACL: Modulation of the renin-angiotensin system in white adipose tissue and skeletal muscle: focus on exercise training. Clin Sci (Lond) 2018, 132(14):1487-1507.

14. Echeverria-Rodriguez O, Del Valle-Mondragon L, Hong E: Angiotensin 1-7 improves insulin sensitivity by increasing skeletal muscle glucose uptake in vivo. Peptides 2014, 51:26-30.

15. Cisternas F, Morales MG, Meneses C, Simon F, Brandan E, Abrigo J, Vazquez $Y$, Cabello-Verrugio C: Angiotensin-(1-7) decreases skeletal muscle atrophy induced by angiotensin II through a Mas receptor-dependent mechanism. Clin Sci (Lond) 2015, 128(5):307-319.

16. Takeshita H, Yamamoto K, Nozato S, Takeda M, Fukada SI, Inagaki T, Tsuchimochi H, Shirai M, Nozato Y, Fujimoto T et al: Angiotensin-converting enzyme 2 deficiency accelerates and angiotensin 1-7 restores age-related muscle weakness in mice. J Cachexia Sarcopenia Muscle 2018, 9(5):975-986.

17. Nozato S, Yamamoto K, Takeshita H, Nozato Y, Imaizumi Y, Fujimoto T, Yokoyama S, Nagasawa M, Takeda M, Hongyo K et al: Angiotensin 1-7 alleviates aging-associated muscle weakness and bone loss, but is not associated with accelerated aging in ACE2-knockout mice. Clin Sci (Lond) 2019, 133(18):2005-2018.

18. Kuba $K$, Imai $Y$, Penninger JM: Multiple functions of angiotensin-converting enzyme 2 and its relevance in cardiovascular diseases. Circ J 2013, 77(2):301-308.

19. Patel VB, Mori J, McLean BA, Basu R, Das SK, Ramprasath T, Parajuli N, Penninger JM, Grant MB, Lopaschuk GD et al: ACE2 Deficiency Worsens Epicardial Adipose Tissue Inflammation and Cardiac Dysfunction in Response to Diet-Induced Obesity. Diabetes 2016, 65(1):85-95.

20. Fu Z, Zhao L, Aylor KW, Carey RM, Barrett EJ, Liu Z: Angiotensin-(1-7) recruits muscle microvasculature and enhances insulin's metabolic action via mas receptor. Hypertension 2014, 63(6):1219-1227.

21. Sabharwal R, Cicha MZ, Sinisterra RD, De Sousa FB, Santos RA, Chapleau MW: Chronic oral administration of Ang-(1-7) improves skeletal muscle, autonomic and locomotor phenotypes in muscular dystrophy. Clin Sci (Lond) 2014, 127(2):101-109.

22. Riquelme C, Acuna MJ, Torrejon J, Rebolledo D, Cabrera D, Santos RA, Brandan E: ACE2 is augmented in dystrophic skeletal muscle and plays a role in decreasing associated fibrosis. PLoS One 2014, 9(4):e93449.

23. Takeshita H, Yamamoto K, Mogi M, Nozato S, Horiuchi M, Rakugi H: Different effects of the deletion of angiotensin converting enzyme 2 and chronic activation of the renin-angiotensin system on muscle weakness in middleaged mice. Hypertens Res 2020, 43(4):296-304.

24. Vinel C, Lukjanenko L, Batut A, Deleruyelle S, Pradere JP, Le Gonidec S, Dortignac A, Geoffre N, Pereira O, Karaz S et al: The exerkine apelin reverses age-associated sarcopenia. Nat Med 2018, 24(9):1360-1371.

25. Takeda M, Yamamoto K, Takemura Y, Takeshita H, Hongyo K, Kawai T, Hanasaki-Yamamoto H, Oguro R, Takami Y, Tatara Y et al: Loss of ACE2 exaggerates high-calorie diet-induced insulin resistance by reduction of GLUT4 in mice. Diabetes 2013, 62(1):223-233.

26. Richter EA, Hargreaves M: Exercise, GLUT4, and skeletal muscle glucose uptake. Physiol Rev 2013, 93(3):993-1017.

27. Esteves JV, Enguita FJ, Machado UF: MicroRNAs-Mediated Regulation of Skeletal Muscle GLUT4 Expression and Translocation in Insulin Resistance. J Diabetes Res 2017, 2017:7267910.

28. Giani JF, Mayer MA, Muñoz MC, Silberman EA, Höcht C, Taira CA, Gironacci MM, Turyn D, Dominici FP: Chronic infusion of angiotensin-(1-7) improves insulin resistance and hypertension induced by a high-fructose diet in rats. American Journal of Physiology-Endocrinology and Metabolism 2009, 296(2):E262-E271.

29. Santos SH, Braga JF, Mario EG, Porto LC, Rodrigues-Machado Mda G, Murari A, Botion LM, Alenina N, Bader M, Santos RA: Improved lipid and glucose metabolism in transgenic rats with increased circulating angiotensin-(1-7). Arterioscler Thromb Vasc Biol 2010, 30(5):953-961.

\section{Publisher's Note}

Springer Nature remains neutral with regard to jurisdictional claims in published maps and institutional affiliations.

Ready to submit your research? Choose BMC and benefit from:

- fast, convenient online submission

- thorough peer review by experienced researchers in your field

- rapid publication on acceptance

- support for research data, including large and complex data types

- gold Open Access which fosters wider collaboration and increased citations

- maximum visibility for your research: over $100 \mathrm{M}$ website views per year

At BMC, research is always in progress.

Learn more biomedcentral.com/submissions 